\title{
Batch Study for Insecticide Carbofuran Adsorption onto Palm-Oil-Fronds-Activated Carbon
}

\author{
Jassem M. Salman \\ Department of Research and Development, Minstry of Industery and Minerals, Baghdad 5815, Iraq \\ Correspondence should be addressed to Jassem M. Salman; jasim_63@yahoo.com
}

Received 2 May 2012; Revised 27 June 2012; Accepted 2 July 2012

Academic Editor: Javier Hernandez-Borges

Copyright (C) 2013 Jassem M. Salman. This is an open access article distributed under the Creative Commons Attribution License, which permits unrestricted use, distribution, and reproduction in any medium, provided the original work is properly cited.

\begin{abstract}
The adsorption of insecticide, carbofuran from aqueous solution onto activated carbon derived from palm oil fronds (PFAC) was investigated through batch study. The effects of both initial concentration and $\mathrm{pH}$ of the carbofuran over the range of 25 to $250 \mathrm{mg} / \mathrm{L}$ and 2 to 12, respectively, on the adsorption of the prepared PFAC were studied in batch experiments. Equilibrium data were fitted to the Langmuir, the Freundlich, and the Temkin isotherm models. The results obtained from application of these models show that the best fits were achieved with the Langmuir model, and a maximum monolayer adsorption capacity of $164 \mathrm{mg} / \mathrm{g}$ was obtained at $30^{\circ} \mathrm{C}$. The regeneration efficiency of spent activated carbon was studied and it was found to be $90.0-96.4 \%$. The results indicated that PFAC has good capability as adsorbent for the removal of carbofuran from aqueous solutions.
\end{abstract}

\section{Introduction}

Pesticides are chemicals, which are commonly used in agriculture to protect crops from pest organisms including insects, plants, fungi, rodents, and nematodes. They may appear as pollutants in water sources and threat to human health because of their toxicity, carcinogenicity, and mutagenicity. In developed countries, drinking water quality has strict regulations regarding pesticides [1].

Presently, on a worldwide basis, intoxications attributed to pesticides have been estimated to be as high as 3 million cases of acute and severe poisoning annually, with many unreported cases and with some 220000 deaths [2]. This situation calls for urgent attention with acceptable solution for the removal of pesticides from water sources. This is because pesticides will continue to be used effectively for pest controls and the responsibility rest on us to find ways of avoiding many of the pesticides poisonings and contaminations that exist today.

Carbofuran is a broad spectrum systemic acaricides, insecticide, and nematocide included in the general group of the carbamate derivative pesticides [3]. It is widely used for the control of soil dwelling and foliar feeding insects including wireworms, white grubs, weevils, stem borers, aphids, and several other insects [4]. Carbofuran is known to be more persistent than other carbamate or organophosphate insecticides [5]. Carbofuran is degraded in water by hydrolysis, microbial decomposition, and photolysis. In the soil, it is degraded by hydrolysis, microbial action, and to a lesser extent, photodecomposition [6]. The maximum acceptable concentration for carbofuran in drinking water [7] is $0.09 \mathrm{mg} / \mathrm{L}$. Determining the level of carbofuran in soil or water has become increasingly important in recent years because of the widespread use of these compounds, which is due to their wide-ranging biological activity and relatively low persistence compared to organochlorine pesticides [8].

There are several methods either independent or in conjunction that have been used for the removal of pesticides from water, such as chemical oxidation with ozone [9], photocatalytic method [10], combined ozone and UV irradiation [11], ozonation [12], membrane filtration [13], and adsorption [14]. Adsorption is one of the most frequently applied methods because of its efficiency, capacity, and applicability on a large scale. The most commonly used adsorbent in adsorption processes is activated carbon due to its efficiency and economic feasibility. Utilization of activated carbon can be in the form of powder, granular, and fiber or cloth. Recently, growing research interest in the 
production of carbon-based-activated carbon has been focused on agricultural by-products. Low-cost adsorbents derived from agricultural wastes have demonstrated outstanding capabilities for the removal of pollutants from wastewater. Therefore, low-cost agricultural waste adsorbents can be viable alternatives to activated carbon for the treatment of contaminated wastewater. The use of cheap and eco-friendly adsorbents have been studied as an alternative substitution to activated carbon for the removal of dyes from wastewater [15].

\section{Experimental}

2.1. Carbofuran. Carbofuran supplied by Sigma-Aldrich Sdn Bhd, Malaysia was used as the adsorbate in this study. Deionized water was used to prepare all the solutions.

2.2. Preparation and Characterization of Activated Carbon. The adsorbent used in this study was PFAC, which was prepared by physiochemical activation using POF under same conditions as optimized in our previous study [16]. Palm oil fronds (POF) were cut into pieces, dried in air until the weight was constant. The dried sample was then crushed using a grinder and thereafter screened to particle size range of $1-4 \mathrm{~mm}$. The screened POF were then carbonized in a stainless steel, vertical tubular reactor, placed in a tube furnace. The temperature of the furnace was ramped from room temperature to $700^{\circ} \mathrm{C}$ at heating rate of $10^{\circ} \mathrm{C} / \mathrm{min}$ and held for $2 \mathrm{~h}$ under nitrogen $(99.995 \%)$ flowing at the rate of $150 \mathrm{~cm}^{3} / \mathrm{min}$. The char produced from the carbonization process was subsequently impregnated with $\mathrm{KOH}$ pellets ( $\mathrm{KOH} / \mathrm{Char}=2.75$ by weight). The impregnated char was thermally treated under nitrogen to a final temperature of $850^{\circ} \mathrm{C}$. Once the final temperature was reached, the nitrogen gas flow was switched over to $\mathrm{CO}_{2}$ and held under that condition for $1 \mathrm{~h}$. The PFAC produced was then cooled to room temperature under nitrogen flow $\left(150 \mathrm{~cm}^{3} / \mathrm{min}\right)$ and thereafter washed with $0.1 \mathrm{M} \mathrm{HCl}$ and hot distilled water to bring the $\mathrm{pH}$ of the washing filtrate to about 7 .

The surface area, pore size distribution, and the pore volume of the developed PFAC were analyzed using Micromeritics (Model ASAP 2020, USA, surface area and porosity analyzer) employing nitrogen adsorption isotherm at $77 \mathrm{~K}$. In order to determine the surface morphology of the PFAC, the sample was examined using Scanning Electron Microscope (SEM), model: Leo Supra 35 VP Field Emission SEM.

\subsection{Batch Equilibrium Studies}

2.3.1. Effect of Carbofuran Initial Concentration and Solution $\mathrm{pH}$. In order to study the effect of carbofuran initial concentration and contact time on the adsorption uptake, $200 \mathrm{~mL}$ of carbofuran solutions with initial concentrations of 25-250 mg/L was prepared in a series of $250 \mathrm{~mL}$ Erlenmeyer flasks, and $0.30 \mathrm{~g}$ of the PFAC was added into each flask covered with glass stopper. The flasks were then placed in an isothermal water-bath shaker at $30^{\circ} \mathrm{C}$, with agitation speed of $120 \mathrm{rpm}$. At specific time intervals, samples were withdrawn for analysis, using a double beam UV-vis spectrophotometer (Shimadzu UV-1700, Japan) at $273 \mathrm{~nm}$, until equilibrium point was reached. The effect of solution $\mathrm{pH}$ on the carbofuran adsorption on PFAC was also examined by varying the initial $\mathrm{pH}$ of the solutions between 2 and 12 (using $0.1 \mathrm{M} \mathrm{HCl}$ ). In a typical run, the carbofuran initial concentration was fixed at $100 \mathrm{mg} / \mathrm{L}$, with activated carbon dosage of $0.30 \mathrm{~g} / 200 \mathrm{~mL}$ and solution temperature of $30^{\circ} \mathrm{C}$.

2.3.2. Equilibrium Data Fitting. Three isotherm models were used to test fit the experimental data, the Langmuir isotherm [17], the Freundlich isotherm [18], and the Timken isotherm [19]. The linear form of the Langmuir model is

$$
\frac{C_{e}}{q_{e}}=\frac{C_{e}}{q_{m}}+\frac{1}{K_{a} q_{m}},
$$

where $C_{e}$ is the equilibrium concentration $(\mathrm{mg} / \mathrm{L}) ; q_{e}$ the amount carbofuran adsorbed at equilibrium (mg/g); $q_{m}$ the adsorption for complete monolayer $(\mathrm{mg} / \mathrm{g}) ; K_{a}$ is the sorption equilibrium constant $(\mathrm{L} / \mathrm{mg})$.

The linear form of Freundlich isotherm is

$$
\ln q_{e}=\ln K_{F}+\left(\frac{1}{n}\right) \ln C_{e}
$$

The constants $K_{F}$ and $1 / n$ of the Freundlich model are the constants indicative of the relative adsorption capacity of the adsorbent and the intensity of the adsorption, respectively.

The Timken isotherm has been used in the form as follows:

$$
q_{e}=B \ln A+B \ln C_{e}
$$

where $B=\mathrm{RT} / b, b$ is the Temkin constant related to heat of sorption $(\mathrm{J} / \mathrm{mol}) ; A$ is the Temkin isotherm constant $(\mathrm{L} / \mathrm{g})$, $\mathrm{R}$ the gas constant $(8.314 \mathrm{~J} / \mathrm{mol} \mathrm{K})$, and $T$ the absolute temperature $(\mathrm{K})$.

2.4. Regeneration of Activated Carbon. The feasibility of regenerating the spent activated carbon was evaluated using ethanol desorption technique [20]. Batch equilibrium tests were performed on the fresh activated carbon prepared, where $100 \mathrm{~mL}$ of carbofuran solution with initial concentration of $200 \mathrm{mg} / \mathrm{L}$ was placed in a $250 \mathrm{~mL}$ Erlenmeyer flasks. $0.30 \mathrm{~g}$ of the fresh PFAC was added into the flask and placed in an isothermal water bath shaker at $30^{\circ} \mathrm{C}$, with agitation speed of $120 \mathrm{rpm}$, for $48 \mathrm{~h}$ until complete equilibrium was attained. The spent activated carbon was then separated from the solution and dried at $105^{\circ} \mathrm{C}$ in an oven. It was thereafter mixed with $100 \mathrm{~mL}$ of $95 \mathrm{vol}$. \% ethanol in an Erlenmeyer flask for the desorption of the adsorbed carbofuran. The flask was kept in the isothermal water-bath shaker at the same temperature for the same time duration as the adsorption tests. Desorption percentage was calculated from (4):

$$
\text { desorption } \%=\left(\frac{C_{\mathrm{de}}}{C_{\mathrm{ad}}}\right) \times 100 \text {. }
$$




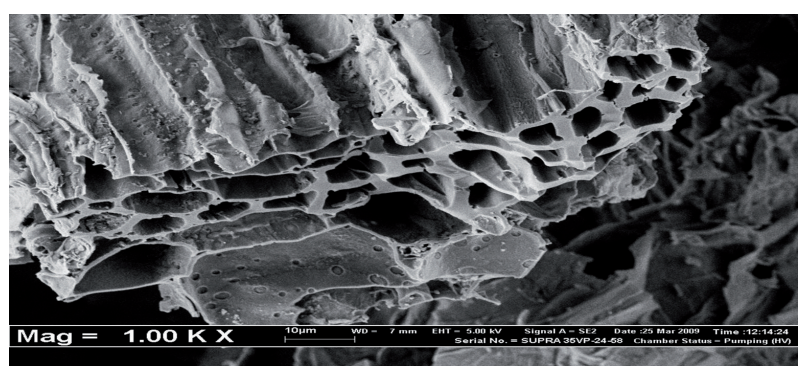

FIGURE 1: Surface morphology of the PFAC (magnifications: 1000x)

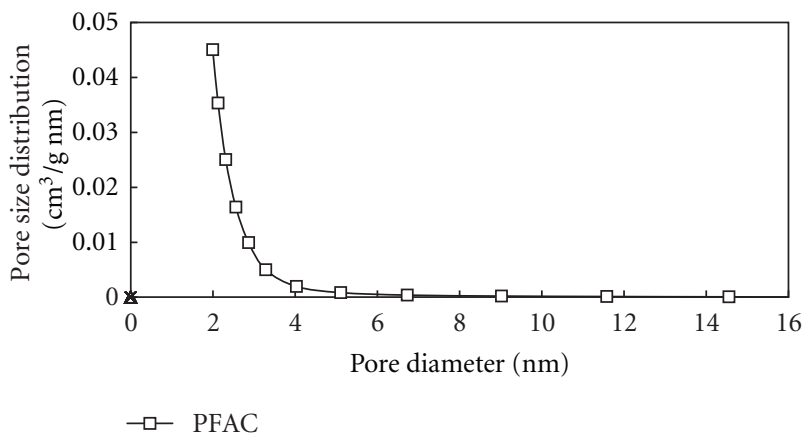

FIgure 2: Pore size distribution of PFAC.

\section{Results and Discussion}

3.1. The Morphological and Textural Characteristics of the Developed PFAC. Figure 1 shows the scanning electron microscopy (SEM) image of the produced PFAC. The PFAC depicts a surface containing a well-developed pores expected of a good absorbent, in which the carbonaceous matters and salts that could have blocked the pores as seen in the precursor had been leached off by the activation process, showing the efficacy of the thermochemical activation method adopted in this investigation.

The Brunauer-Emmett-Teller (BET) surface analysis shows $\left(1237.13 \mathrm{~m}^{2} / \mathrm{g}, 0.66723 \mathrm{~cm}^{3} / \mathrm{g}\right.$, and $2.157 \mathrm{~nm}$, values for surface area, pore volume, and pore diameter, resp.) for the prepared activated carbon. Figure 2 shows the pore size distributions of PFAC. As can be seen from this plot, singular sharp peaks were detected in the range of $2-3 \mathrm{~nm}$. The narrow pore size distributions indicated the suitability of activated carbon prepared for separation purposes. The development of porosity on the activated carbons by $\mathrm{KOH}$ activation is associated with gasification reaction. This phenomenon could be explained by the fact that $\mathrm{KOH}$ is reduced to its metallic oxide by dehydration during the activation process, and it was observed that at high temperatures above $420^{\circ} \mathrm{C}, \mathrm{KOH}$ melts and its oxide component reacts with carbon dioxide present in the medium to form $\mathrm{K}_{2} \mathrm{CO}_{3}$ which assist to develop wider pores in the activated carbon material.

3.2. Effect of Initial Concentration and Agitation Time on Carbofuran Adsorption. The effect of carbofuran initial concentration and agitation time on the carbofuran adsorption onto the PFAC is shown in Figure 3. It is clear that the amount

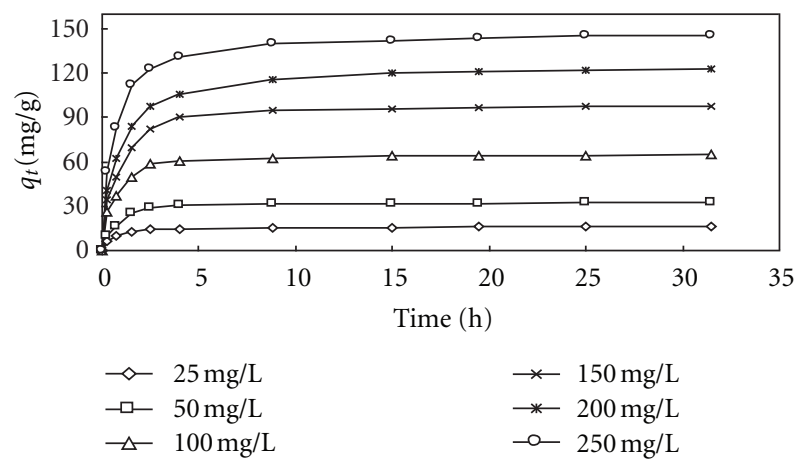

FIGURE 3: Effect of carbofuran initial concentration and agitation time on carbofuran adsorption capacity.

TABle 1: Langmuir, Freundlich, and Temkin isotherm model parameters and correlation coefficients for adsorption of carbofuran on PFAC at $30^{\circ} \mathrm{C}$.

\begin{tabular}{lccc}
\hline Isotherm models & \multicolumn{3}{c}{ Parameters } \\
\hline Langmuir & $q_{m}(\mathrm{mg} / \mathrm{g})$ & $b(\mathrm{~L} / \mathrm{mg})$ & $R^{2}$ \\
& 164 & 0.236 & 0.993 \\
\hline Freundlich & $K_{F}\left(\mathrm{mg} / \mathrm{g}(\mathrm{L} / \mathrm{mg})^{1 / n}\right)$ & $1 / n$ & $R^{2}$ \\
& 31.31 & 0.521 & 0.887 \\
\hline Temkin & $A(\mathrm{~L} / \mathrm{g})$ & $B$ & $R^{2}$ \\
& 1.13 & 32.51 & 0.958 \\
\hline
\end{tabular}

of carbofuran adsorbed, $q_{t}$ increased onto PFAC surface. The adsorption uptake at equilibrium was found to increase with an increase in the initial insecticide concentration as appeared in Figure 3, which shows that longer contact times were required to reach equilibrium by the carbofuran solutions of higher initial concentrations.

The contact time needed for carbofuran solutions with initial concentration of $25-150 \mathrm{mg} / \mathrm{L}$ to reach equilibrium on PFAC was around 2-4 h; at the mean time the contact times for higher initial concentrations (200-250 mg/L) equilibrium times of $8-10 \mathrm{~h}$ were required.

Adsorption of carbofuran was fast due to the high affinity of the interacting groups on the surface of the activated carbon. The high adsorption rate at the beginning of adsorption was due to the adsorption of carbofuran to the exterior surface of the adsorbent. The high adsorption uptake of activated carbons prepared in this work was due to the presence of functional groups such as hydroxyl, carbonyl which dissociate and hence the electrostatic attraction between the activated carbon surface and insecticide takes place. Similar trend has been reported for carbofuran adsorption onto carbon slurry [21]. The rate of uptake is rapid in the beginning and the rate of adsorption was found to depend on the initial concentration of pesticide.

3.3. Effect of Solution pH on Carbofuran Adsorption. The effect of $\mathrm{pH}$ on carbofuran adsorption was studied by varying the $\mathrm{pH}$ from 2 to 12 using $200 \mathrm{~mL}$ of a $100 \mathrm{mg} / \mathrm{L}$ fixed initial concentration of carbofuran at $30^{\circ} \mathrm{C}$. The equilibrium adsorption of carbofuran was found to decrease slightly when 
TABLE 2: Comparison of the maximum adsorption uptake of carbofuran insecticide onto different type of activated carbons.

\begin{tabular}{lccc}
\hline Activated carbon & Pesticide initial concentration (mg/L) & Adsorption uptake (mg/g) & Reference \\
\hline Banana stalks AC & $50-250$ & 156.3 & {$[6]$} \\
Iraqi date seeds AC & $25-250$ & 137.04 & 96.15 \\
Commercial granular AC, Filtersorb 300 (GAC F300) & $50-225$ & 97.1 & {$[13]$} \\
Commercial AC (CAC-F200) & $25-250$ & $1.54-1.65$ & {$[22]$} \\
Coal fly ash AC & $50-250$ & 2.39 & $164]$ \\
Chestnut shells AC & $10-100$ & {$[25]$} \\
Palm fronds AC & $25-250$ & This study \\
\hline
\end{tabular}

the initial $\mathrm{pH}$ of the aqueous solution was increased from 2 to 12 . This may be due to the presence of excess $\mathrm{H}^{+}$ions which accelerates the removal of the carbofuran with the anion $\mathrm{OH}^{-}$in the aqueous solution. It is also possible that the surface properties of the activated carbon have been altered as a result of the $\mathrm{pH}$ of the solution. Thus, the surface charge would depend on the solution $\mathrm{pH}$ and the surface characteristics of the carbon [26]. Similar trend was observed in the adsorption of phenol (over the $\mathrm{pH}$ range of 2-8) on oil palm empty fruit-bunches-activated carbon [26] and the adsorption of Lambda-Cyhalothrin by oil shale ash [27]. Krishna and Philip (2008) reported that the adsorption of carbofuran was significant at $\mathrm{pH}$ value of 2 and from $\mathrm{pH} 8$ to 10 there was a slight reduction in adsorption capacity for carbofuran [28]. This may be due to the masking of functional groups at high $\mathrm{pH}$. The effect of $\mathrm{pH}$ on carbofuran adsorption was also studied by Gupta et al. (2006) and they reported that when at lower $\mathrm{pH}$, carbofuran adsorption was higher [21].

It has been observed that a change in solution $\mathrm{pH}$ would also alter the properties of pesticides molecules and consequently its adsorption uptake. Additionally, the surface functional groups of adsorbate makes adsorption process complex by the type of charge characteristics present at the adsorbent surface [29].

3.4. Adsorption Isotherm. The equilibrium data for carbofuran adsorption on PFAC were modeled with three linearized expressions of the Langmuir, the Freundlich, and the Temkin isotherm models (Figures not shown). Table 1 summarizes all the constants and correlation coefficients, $R^{2}$ of these three isotherm models at $30^{\circ} \mathrm{C}$. The Langmuir model yielded the best fit with $R^{2}$ which was higher than 0.993 . The monolayer adsorption capacity according to Langmuir model was $164 \mathrm{mg} / \mathrm{g}$.

Table 2 compares the maximum adsorption capacity of various activated carbons (ACs) which used as adsorbents for removal of carbofuran from aqueous solutions. The table shows that the adsorption capacity of PFAC is high compared to to the other adsorbents.

3.5. Regeneration of Activated Carbon. (PFAC) that adsorbed carbofuran was regenerated by ethanol. The desorption of carbofuran from spent PFAC was repeated for four cycles for adsorption and four cycles for desorption using the same activated carbon for the starting cycle. The regeneration efficiency was found to be $90-96.4 \%$. This result indicates that the prepared activated carbon has a good regeneration and reusability characteristics for the adsorption of carbofuran and can be used as an alternative to the presently available commercial activated carbons.

\section{Conclusion}

This work examined the feasibility of activated carbon prepared from oil palm fronds for the adsorption of carbofuran insecticide from aqueous solutions over a wide range of concentrations. It was found that the PFAC was very effective for this purpose. Equilibrium data were fitted to the Langmuir, Freundlich, and Temkin isotherms, and the equilibrium data were best described by the Langmuir isotherm model, with the maximum monolayer adsorption capacity of $164 \mathrm{mg} / \mathrm{g}$. Ethanol desorption technique was efficient in regenerating the spent activated carbon, and this provides a good ground for the reusability of the PFAC in subsequent adsorption runs.

\section{References}

[1] E. Ayranci and N. Hoda, "Adsorption of bentazon and propanil from aqueous solutions at the high area activated carbon-cloth," Chemosphere, vol. 57, no. 8, pp. 755-762, 2004.

[2] T. Kumazawa and O. Suzuki, "Separation methods for amino group-possessing pesticides in biological samples," Journal of Chromatography B, vol. 747, no. 1-2, pp. 241-254, 2000.

[3] F. J. Benitez, J. L. Acero, and F. J. Real, "Degradation of carbofuran by using ozone, UV radiation and advanced oxidation processes," Journal of Hazardous Materials, vol. 89, no. 1, pp. 51-65, 2002.

[4] S. P. Kale, N. B. K. Murthy, and K. Raghu, "Degradation of 14C-carbofuran in soil using a continuous flow system," Chemosphere, vol. 44, no. 4, pp. 893-895, 2001.

[5] J. M. Brasel, A. C. Collier, and C. A. Pritsos, "Differential toxic effects of Carbofuran and Diazinon on time of flight in pigeons (Columba livia): potential for pesticide effects on migration," Toxicology and Applied Pharmacology, vol. 219, no. 2-3, pp. 241-246, 2007.

[6] J. M. Salman and B. H. Hameed, "Removal of insecticide carbofuran from aqueous solutions by banana stalks activated carbon," Journal of Hazardous Materials, vol. 176, no. 1-3, pp. 814-819, 2010.

[7] U. S. Environmental Protection Agency, Health AdvisoryCarbofuran, Office of Drinking Water, 1985. 
[8] M. Gavrilescu, "Fate of pesticides in the environment and its bioremediation," Engineering in Life Sciences, vol. 5, no. 6, pp. 497-526, 2005.

[9] R. Broséus, S. Vincent, K. Aboulfadl et al., "Ozone oxidation of pharmaceuticals, endocrine disruptors and pesticides during drinking water treatment," Water Research, vol. 43, no. 18, pp. 4707-4717, 2009.

[10] Y. Lu, D. Wang, C. Ma, and H. Yang, "The effect of activated carbon adsorption on the photocatalytic removal of formaldehyde," Building and Environment, vol. 45, no. 3, pp. 615-621, 2010.

[11] L. Yeasmin, S. A. MacDougall, and B. D. Wagner, "UV-A photochemistry of the pesticide azinphos-methyl: generation of the highly fluorescent intermediate N-methylanthranilic acid," Journal of Photochemistry and Photobiology A, vol. 204, no. 2-3, pp. 217-223, 2009.

[12] R. Rajeswari and S. Kanmani, "A study on synergistic effect of photocatalytic ozonation for carbaryl degradation," Desalination, vol. 242, no. 1-3, pp. 277-285, 2009.

[13] J. M. Salman, V. O. Njoku, and B. H. Hameed, "Bentazon and carbofuran adsorption onto date seed activated carbon: kinetics and equilibrium," Chemical Engineering Journal, vol. 173, pp. 361-368, 2011.

[14] V. R. Midathana and V. S. Moholkar, "Mechanistic studies in ultrasound-assisted adsorption for removal of aromatic pollutants," Industrial and Engineering Chemistry Research, vol. 48, no. 15, pp. 7368-7377, 2009.

[15] A. Demirbas, "Agricultural based activated carbons for the removal of dyes from aqueous solutions: a review," Journal of Hazardous Materials, vol. 167, no. 1-3, pp. 1-9, 2009.

[16] J. M. Salman and B. H. Hameed, "Effect of preparation conditions of oil palm fronds activated carbon on adsorption of bentazon from aqueous solutions," Journal of Hazardous Materials, vol. 175, no. 1-3, pp. 133-137, 2010.

[17] I. Langmuir, "The adsorption of gases on plane surfaces of glass, mica and platinum," The Journal of the American Chemical Society, vol. 40, no. 9, pp. 1361-1403, 1918.

[18] H. M. F. Freundlich, "Over the adsorption in solution," Journal of Physical Chemistry, vol. 57, pp. 385-470, 1906.

[19] M. I. Temkin and V. Pyzhev, "Kinetics of ammonia synthesis on promoted iron catalys," Acta Physiochemical USSR, vol. 12, pp. 327-356, 1940.

[20] W. Tanthapanichakoon, P. Ariyadejwanich, P. Japthong, K. Nakagawa, S. R. Mukai, and H. Tamon, "Adsorption-desorption characteristics of phenol and reactive dyes from aqueous solution on mesoporous activated carbon prepared from waste tires," Water Research, vol. 39, no. 7, pp. 1347-1353, 2005.

[21] V. K. Gupta, I. Ali, Suhas, and V. K. Saini, "Adsorption of 2,4$\mathrm{D}$ and carbofuran pesticides using fertilizer and steel industry wastes," Journal of Colloid and Interface Science, vol. 299, no. 2, pp. 556-563, 2006.

[22] J. M. Salman and B. H. Hameed, "Adsorption of 2,4-dichlorophenoxyacetic acid and carbofuran pesticides onto granular activated carbon," Desalination, vol. 256, no. 1-3, pp. 129-135, 2010.

[23] J. M. Salman, F. M. Abid, and A. A. Muhammed, "Adsorption of carbofuran insecticide from aqueous solution using commercial activated carbon," International Journal of Chemical Sciences, vol. 9, no. 2, pp. 557-564, 2011.

[24] K. Kumari, R. P. Singh, and S. K. Saxena, "Adsorption thermodynamics of carbofuran on fly ash," Colloids and Surfaces, vol. 33, no. 1-2, pp. 55-61, 1988.
[25] G. Zuhra Memon, M. I. Bhanger, and M. Akhtar, "The removal efficiency of chestnut shells for selected pesticides from aqueous solutions," Journal of Colloid and Interface Science, vol. 315, no. 1, pp. 33-40, 2007.

[26] M. Z. Alam, S. A. Muyibi, M. F. Mansor, and R. Wahid, "Activated carbons derived from oil palm empty-fruit bunches: application to environmental problems," Journal of Environmental Sciences, vol. 19, no. 1, pp. 103-108, 2007.

[27] Z. Al-Qodah, A. T. Shawaqfeh, and W. K. Lafi, "Adsorption of pesticides from aqueous solutions using oil shale ash," Desalination, vol. 208, no. 1-3, pp. 294-305, 2007.

[28] K. R. Krishna and L. Philip, "Adsorption and desorption characteristics of lindane, carbofuran and methyl parathion on various Indian soils," Journal of Hazardous Materials, vol. 160, no. 2-3, pp. 559-567, 2008.

[29] M. Sathishkumar, A. R. Binupriya, D. Kavitha et al., "Adsorption potential of maize cob carbon for 2,4-dichlorophenol removal from aqueous solutions: equilibrium, kinetics and thermodynamics modeling," Chemical Engineering Journal, vol. 147, no. 2-3, pp. 265-271, 2009. 

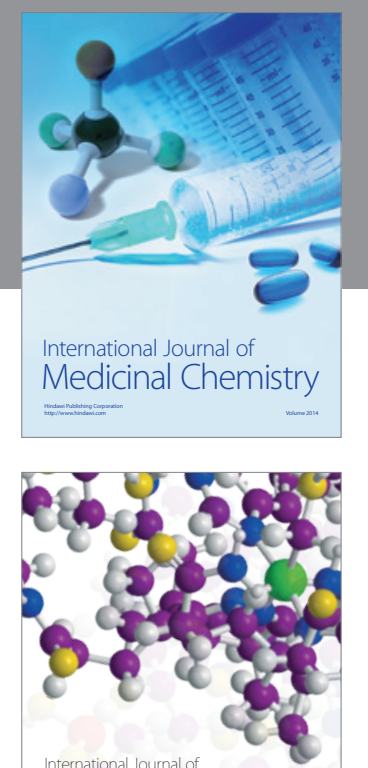

\section{Carbohydrate} Chemistry

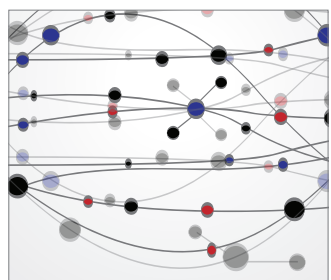

The Scientific World Journal
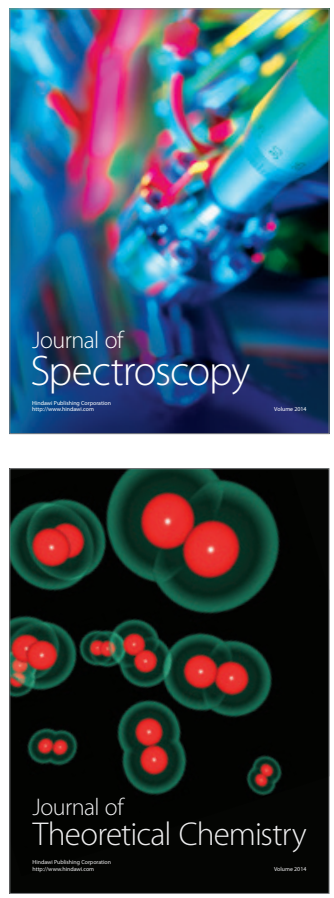
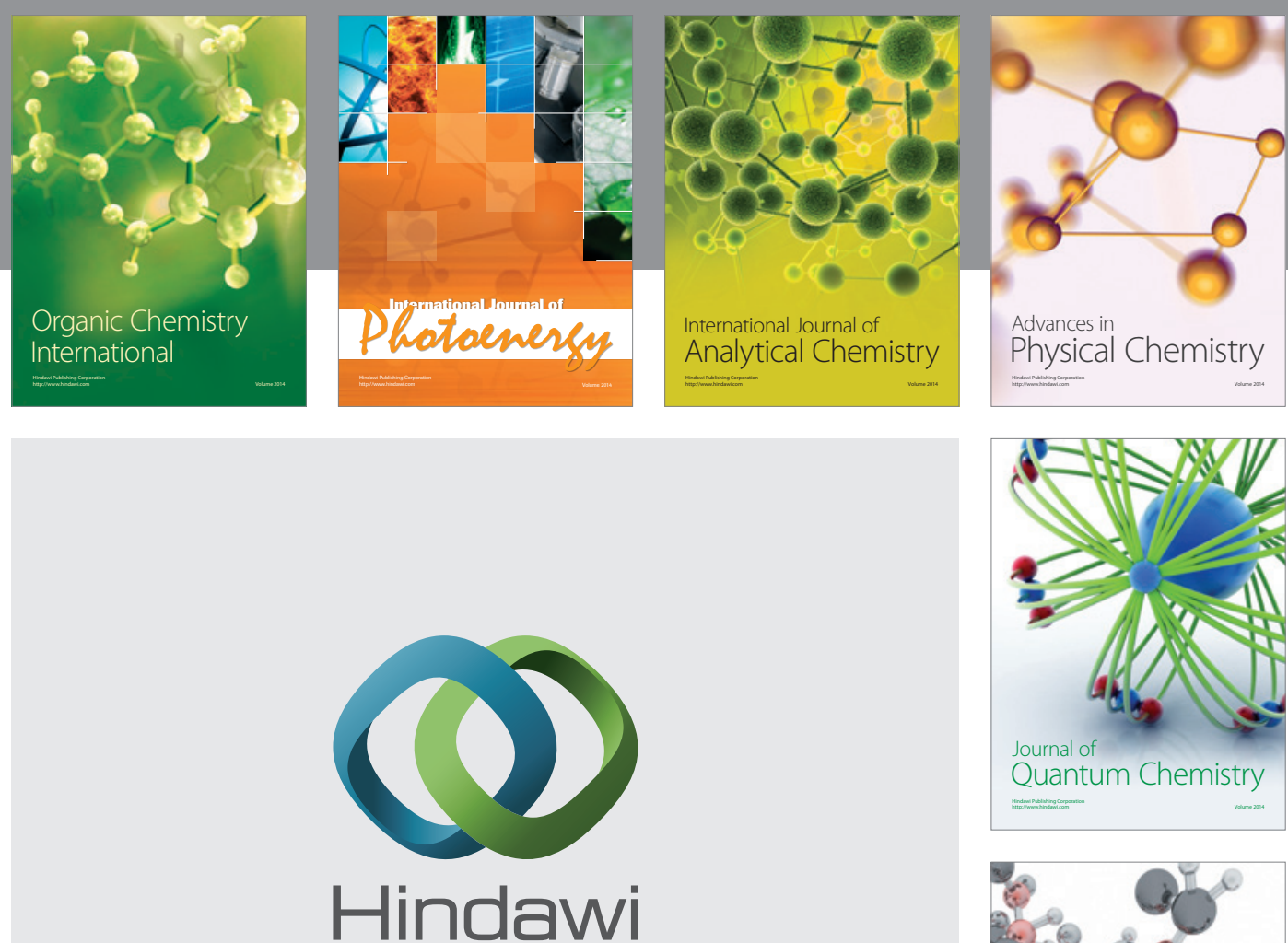

Submit your manuscripts at

http://www.hindawi.com

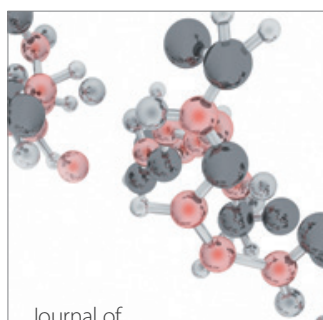

Analytical Methods

in Chemistry

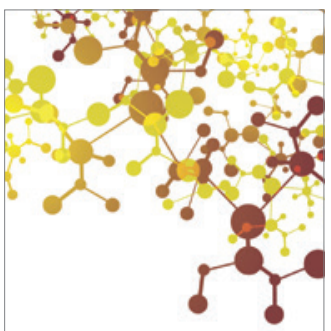

Journal of

Applied Chemistry

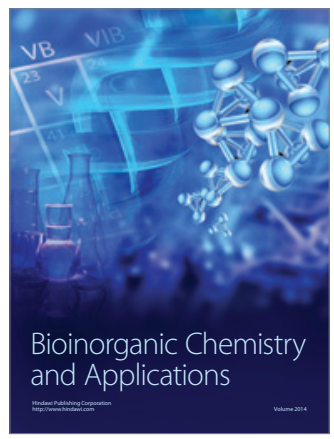

Inorganic Chemistry
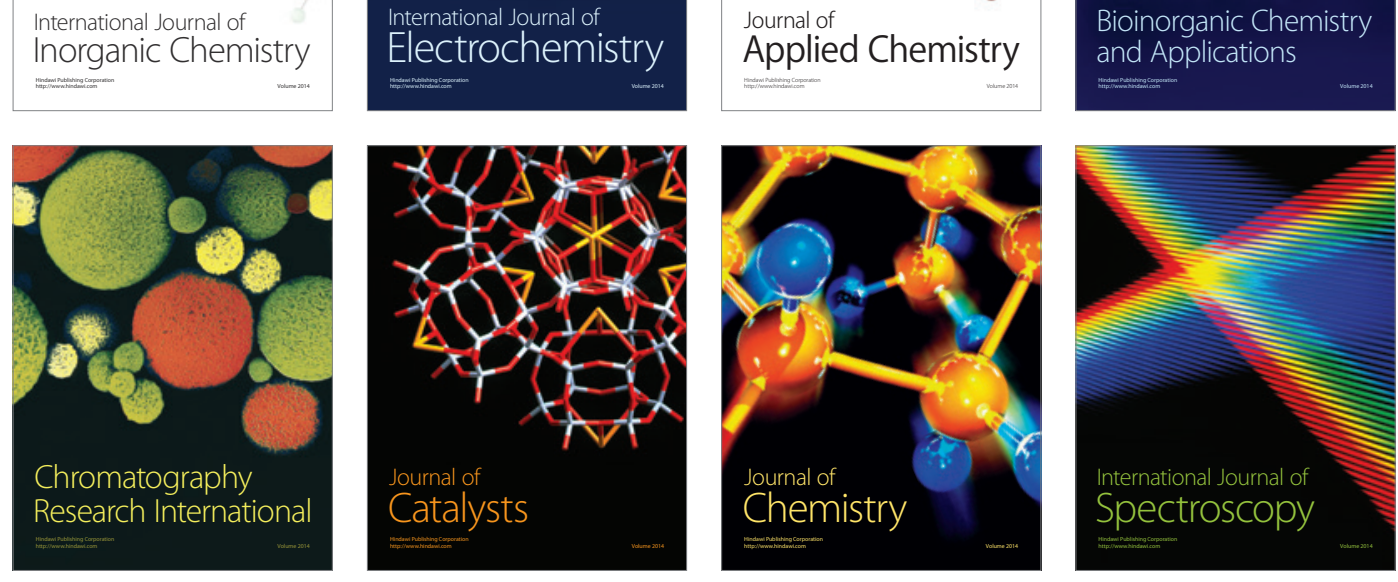